Rachel Zuanon, Melissa Ramos da Silva Oliveira, Cláudio Lima Ferreira, Evandro Ziggiatti Moneiro *

\title{
Memória, emoções e sentimentos: impactos na percepção espacial e afetiva da área urbana central de Campinas
}

Rachel Zuanon é artista midiática e designer. Docente no Curso de Artes Visuais e professora/pesquisadora junto às áreas de Processo Criativo em Composição Artística e de Arte e Tecnologia (IA-UNICAMP). Professora e pesquisadora do PPG-AV (IA-UNICAMP) e do PPG-ATC (FEC-UNICAMP). Co-fundadora e coordenadora da DASMind-UNICAMP [Design, Art, Space and Mind: Transdisciplinary Cooperation Network in Research and Innovation]. Coordenadora de Pesquisa e Extensão (IA-UNICAMP). Coordenadora do LIS (IA-UNICAMP). Membro do Conselho da GAIA (Galeria de Arte/IA-UNICAMP). Com prêmios nacionais e internacionais, desde 1998, dedica sua pesquisa e produções à cooperação Neurociência e Processos Criativos e Projetuais.<rzuanon@unicamp.br> ORCID: 0000-0002-7917-9917
Resumo Por meio da cooperação transdisciplinar entre Arquitetura-Urbanismo-Neurociência, esta pesquisa investiga a ação da área central da cidade de Campinas (São Paulo - Brasil) sobre a percepção espacial e as memórias afetivas dos seus habitantes/usuário. Para tanto, realiza procedimento em campo com 266 voluntários, direcionado a evocar as memórias declarativas semânticas dos participantes sobre este espaço/lugar, e registra-las como depoimentos e desenhos autorais. Os principais resultados evidenciam a modulação destas memórias pelas emoções e sentimentos e discutem: a) a inexistência de identificação e a aversão dos habitantes/usuários à área central da cidade; b) o sentimento de insegurança deflagrado pelo espaço urbano em seus cidadãos; c) assim como estes fatores ameaçam o equilíbrio homeostático destes sujeitos. Como principal contribuição destaca-se o papel e a responsabilidade das políticas públicas e dos profissionais dos campos da Arquitetura, Urbanismo e Design nos modos do cidadão sentir, perceber e ocupar o espaço urbano.

Palavras chave Arquitetura-Urbanismo-Neurociência, Percepção Espacial, Memória Afetiva, Emoções e Sentimentos, Campinas. 
Melissa Ramos da Silva Oliveira é Arquiteta, professora do Programa de Pós-graduação em Arquitetura e Cidade e do curso de graduação em Arquitetura e Urbanismo, ambos da Universidade Vila Velha. Possui mestrado e doutorado em Geografia pela UNICAMP, especialização em Restauro Arquitetônico pela PUC-Campinas. Fundadora e líder do grupo de pesquisa Arquitetura, Cidade e Patrimônio. Membro da DASMind-UNICAMP [Design, Art, Space and Mind: Transdisciplinary Cooperation Network in Research and Innovation]. Possui pesquisas científicas pautadas na cooperação entre Patrimônio Cultural, Arquitetura e Neurociência. >melissa.oliveira@uvv.br> ORCID: 0000-0002-8529-5180

\section{Memory, emotions and feelings: impacts on spatial and affective perception of the central urban area of Campinas}

Abstract Departing from a transdisciplinary cooperation between Architecture-Urbanism-Neuroscience, this research investigates the action of the central area of the city of Campinas (São Paulo - Brazil) on the spatial perception and affective memories of its inhabitants / user. To this purpouse, it carries out a field procedure with 266 volunteers, aimed at evoking the participants' semantic declarative memories about this space / place, and registering them as statements and authorial drawings. The main results declare the modulation of these memories by emotions and feelings and they discuss: a) the lack of identification and the aversion of the inhabitants / users to the central area of the city; $b$ ) the feeling of insecurity triggered by the urban space in its citizens; c) as well as these factors threaten the homeostatic balance of these subjects. As the main contribution, the role and responsibility of public policies and the professionals in the fields of Architecture, Urbanism and Design stand out in the ways of citizens feeling, perceiving and occupying the urban space.

Keywords Architecture-Urbanism-Neuroscience, Spatial Perception, Affective Memory, Emotions and Feelings, Campinas.

\section{Memoria, emociones y sentimientos: impactos en la percepción espacial y afectiva del área urbana central de Campinas}

Resumen Através de la cooperación transdisciplinaria entre Arquitectura-Urbanismo-Neurociencia, esta investigación examina la acción del área central de la ciudad de Campinas (São Paulo - Brasil) sobre la percepción espacial y los recuerdos afectivos de sus habitantes / usuarios. Con este fin, lleva a cabo un procedimiento de campo con 266 voluntarios, con el objetivo de evocar los recuerdos semánticos declarativos de este espacio / lugar y registrarlos como declaraciones y dibujos de autor. Los resultados principales muestran la modulación de estos recuerdos por emociones y sentimientos y discuten: a) la falta de identificación y la aversión de los habitantes / usuarios al área central de la ciudad; b) el sentimiento de inseguridad provocado por el espacio urbano en sus ciudadanos; c) así como estos factores amenazan el equilibrio homeostático de estos sujetos. Como contribución principal, se destacan el papel y la responsabilidad de las políticas públicas y de los profesionales en los campos de Arquitectura, Urbanismo y Diseño en la forma en que los ciudadanos sienten, perciben y ocupan el espacio urbano.

Palabras clave Arquitectura-Urbanismo-Neurociencia, Percepción espacial, Memoria afectiva, Emociones y sentimientos, Campinas. 
Evandro Ziggiatti Monteiro é Arquiteto e Urbanista, professor do Programa de Pós-graduação em Arquitetura, Tecnologia e Cidade, da FEC-UNICAMP. Suas pesquisas estão relacionadas à morfologia urbana, suas mudanças e impactos na paisagem urbana. Entre 2013 e 2016 foi coordenador do Curso de Arquitetura e Urbanismo da UNICAMP. Desde 2010, é coordenador associado do FLUXUS, Laboratório de Ensinagem em Redes Técnicas e Sustentabilidade Socioambiental. Co-fundador e co-coordenador da DASMind-UNICAMP [Design, Art, Space and Mind: Transdisciplinary Cooperation Network in Research and Innovation]. <evandrozig@fec.unicamp.br> ORCID: 0000-0002-6304-1614

\section{Introdução}

Andar pelo centro de distintas cidades que compõem o território brasileiro, é entrar em um mundo em que formas, cores, texturas, cheiros e sons se misturam. Despertam emoções, sentimentos e afetos, a partir de sensações e percepções múltiplas. Significa lidar com o enfrentamento de mundos contraditórios e antagônicos, cravados em uma só realidade. O novo convive com o antigo, nem sempre de forma harmônica. Aqueles que têm presença e visibilidade tentam impor-se ao mundo da ausência e dos excluídos. A rapidez e a efemeridade da produção capitalista, que desenham os espaços urbanos, entram em conflito na coexistência com os homens lentos ${ }^{1}$. A cidade formal convive com a informal. Os espaços públicos não legitimados e consequentemente subutilizados, tornam-se territorialidades do crime e da prostituição.

Assim como em outras cidades brasileiras, andar pelo centro da cidade de Campinas², localizada no estado de São Paulo, é circular por vias congestionadas e paralisadas; por calçadas e ruas estreitas, que esmagam o alto fluxo de veículos e pessoas; por mundos e tempos antagônicos: executivos apressados; donas de casa preocupadas; consumidores tranquilos observam vitrines, ao mesmo tempo outros se apressam na busca por liquidações; vendedores autônomos disputam espaços entre carros e pedestres; 'flanelinhas' zelam pelos carros à espera de seus donos; religiosos pregam em voz alta no meio das praças, ao lado dos artistas de rua e dos seus trabalhos artísticos, enquanto mendigos ganham algum trocado para seu sustento.

o barulho intenso cria o emaranhado sonoro composto pelo burburinho de vozes e gritos; pelas buzinas; pelos roncos dos motores; pelos megafones de políticos e das caixas de som das lojas. Pichações e anúncios publicitários se justapõem na poluição visual, que oculta a fachada dos edifícios e impacta os referenciais e o sentido de localização no espaço urbano. O ritmo acelerado não acompanha o tempo para a observação da paisagem circundante. Os espaços públicos deixam de ser áreas de convívio, para se tornarem locais de passagem. A sociabilidade se esvai com a efemeridade do convívio. Sujeira, poluição e ruído. Excesso de informação. Pressa e confusão. Movimentos alternados de usos e esvaziamentos. Diversidades construídas na aproximação e repulsa de emoções e sentimentos diversos.

Também a exemplo de outras cidades brasileiras, a área central de Campinas corresponde a um espaço físico organizado e reorganizado pelas intervenções urbanísticas conduzidas por forças políticas e econômicas. No passado, abrigava tanto as instâncias de governo, o comércio e o lazer, quanto as moradias das famílias de maior poder aquisitivo. Com a expansão, a cidade é marcada por um modelo residencial de suburbanização e as atividades mais nobres deslocam-se para outras regiões. Enquanto o centro se populariza e passa a sediar o comércio popular, serviços públicos e trabalhadores informais, sobretudo em horário comercial. A pouca atividade noturna corrobora à expansão da violência e da prostituição, e contribuem para definir um cenário de degradação. "É uma profunda ironia que fre- 
quentemente a cidade possa parecer um lugar assustador. Construída para corrigir a aparente confusão e o caos da natureza, a cidade em si mesma se transforma em um meio ambiente físico desorientador" (TUAN, 1995).

Todas essas características evidenciam o espaço vivido, definido pelas práticas espaciais cotidianas. Tais práticas estabelecem simultaneamente os lugares; a relação do local com o global; a representação dos espaços cotidianos comuns e dos espaços privilegiados, afetada por sua existência como símbolo favorável ou não. Ao tomar este cenário como base, podemos avançar ao conceito de apropriação do espaço/lugar, que corresponde à maneira pela qual ele é ocupado por objetos, atividades (usos), indivíduos, classes ou outros grupos sociais (LEFEBVRE, 1974).

Essa maneira de se apropriar do espaço/lugar está intimamente relacionada às emoções e aos sentimentos que este espaço/lugar desperta, e a como estas emoções e sentimentos modulam os mapas cerebrais e as memórias dos seus habitantes/usuários (LIMA JÚNIOR, ZUANON, 2018). No caso do presente artigo, este enfoca a emoção do medo e os sentimentos de risco e insegurança que modulam as memórias declarativas semânticas presentes nos mapas cerebrais de habitantes/usuários do centro da cidade de Campinas. Tais memórias, as quais contém informações sobre o ambiente circundante, são evocadas nos participantes dessa pesquisa, e ganham materialidade no conteúdo reportado por estes em entrevistas, bem como nas representações gráficas realizadas pelos mesmos, e que compõem os desenhos deste espaço/lugar. Nestes âmbitos, problemas urbanos como descaso político social, violência, degradação da infraestrutura e do meio ambiente eclodem como tatuagens involuntárias, as quais cravam as imagens mentais que habitam os mapas cerebrais desses moradores e usuários, ferem a 'pele' da cidade e distorcem os afetos por esta.

A partir dessa perspectiva e de abordagem subsidiada na cooperação entre a Arquitetura, o Urbanismo e a Neurociência, este artigo discute os impactos desses problemas urbanos sobre o organismo dos habitantes/ usuários do centro de Campinas, especialmente quanto: à ausência de identificação e à repulsa ao espaço público; à restrição do uso do espaço urbano e da possibilidade dos cidadãos "viverem" a cidade; à ameaça ao equilíbrio homeostático. Entende-se que investigações desta natureza corroboram ao desenvolvimento socioeconômico urbano ao explicitarem a responsabilidade das políticas públicas, assim como dos arquitetos, designers e urbanistas nos modos do ser humano sentir, perceber, e se apropriar desse espaço. 


\section{Memórias moduladas por emoções e sentimentos}

A memória compreende um processo que envolve a aquisição, a formação, a conservação e a evocação de informações (LENT, 2008). Damásio (2011) a descreve como o conjunto "das atividades sensitivas e motoras relacionadas à interação entre organismo e objeto" (pg. 169). Ou seja, as memórias constituem o acervo único de dados advindos da experiência pessoal. Associadas às características genéticas, as memórias definem o indivíduo, influenciam sua personalidade. A identidade dos povos advém das memórias comuns a todos os seus integrantes. As memórias abarcam a história de cada cidade, país, povo, civilização, assim como as lembranças individuais dos animais e das pessoas. As memórias são codificadas por neurônios, armazenadas em redes neurais e evocadas pelas mesmas redes, nas quais foram armazenadas, ou por outras (CAMMAROTA, BEVILAQUA e IZQUIERDO, 2008).

As emoções, os estados de ânimo, o nível de alerta, a ansiedade e o estresse modulam fortemente as memórias do ser humano. Um indivíduo pouco alerta ou estressado não formará memórias corretamente. Outro submetido a alto nível de ansiedade, poderá esquecer tudo o que aprendeu. Ainda, outro estressado no momento da evocação de suas memórias, apresentará dificuldades para recorda-las. Em contrapartida, um indivíduo alerta as lembrará prontamente. Ou seja, vários sistemas moduladores atuam, de modo satisfatório ou não, sobre os mecanismos que regem as memórias humanas. A modulação da aquisição e das fases iniciais da consolidação das memórias ocorre praticamente ao mesmo tempo e envolve dois aspectos: 1) a distinção entre as memórias com maior carga emocional das demais, de modo a garantir que as primeiras sejam melhor registradas que as outras; 2) o acréscimo de informação neuro-humoral ou hormonal ao conteúdo das memórias em situações de ansiedade ou estresse (IZQUIERDO, 2011).

Enfatiza-se assim o papel das emoções, positivas ou negativas, bem como dos sentimentos que as seguem, como moduladores das memórias humanas e também como componentes obrigatórios das nossas experiências sociais (DAMÁSIO, 2004).

As emoções configuram experiências subjetivas em curto prazo. Já os humores definem uma experiência emocional persistente, subjetiva e sustentada. Enquanto as funções de memória estão amplamente distribuídas entre as áreas límbicas e não-límbicas do encéfalo, as emoções são mediadas no interior do sistema límbico pela amígdala, por áreas do hipotálamo, pela área septal, núcleos anteriores do tálamo, córtex da porção anterior do cíngulo e pelo córtex de associação límbico (LUNDY-EKMAN, 2004). A amígdala desempenha papel crucial no corpo social, ao interpretar as expressões faciais e os sinais sociais (YOUNG et al, 1995).

As emoções são desencadeadas por imagens de pessoas, de animais, de objetos, de ambientes ou por fenômenos, do presente ou do passado, quando recordados. Elas moldam nossas percepções sobre os seres e as coi- 
sas do mundo, bem como influenciam nossas ações. As imagens mentais de determinada situação e/ou ambiente, nos quais o indivíduo se encontra, afetam o seu maquinário emocional. Sejam estas imagens formuladas no momento atual, evocadas da memória, ou criadas na imaginação, todas carregam o potencial de deflagrar reações emocionais em cadeia no corpo humano (DAMÁSIO, 2011). Cada experiência da vida, especialmente aquelas vinculadas a problemas sociais, é acompanhada por algum grau de emoção, por menor que este seja (DAMÁSIO, 2004).

Neste contexto, importa enfatizar os impactos às funções de todos os órgãos humanos decorrentes dos pensamentos e das emoções vivenciados pelo indivíduo. Isso se deve à comunicação bidirecional entre o sistema nervoso e o sistema imunológico. Por exemplo, as respostas do corpo imediatas aos sentimentos de ameaça, risco e insegurança envolvem alterações somáticas, autônomas e hormonais, as quais incluem aumento da tensão muscular e da frequência cardíaca, dilatação das pupilas e interrupção da digestão. Tais respostas podem perturbar a homeostase, ou seja, perturbar os processos de regulação da vida, bem como os estados decorrentes de uma vida bem regulada.

Essa perturbação também pode ser denominada como resposta ao estresse. Quando um indivíduo se sente ameaçado, por qualquer motivo do presente ou do passado, essa resposta ao estresse garante o aumento da força e da energia deste indivíduo, com o objetivo de oferecer a este as condições orgânicas favoráveis ao enfrentamento da situação ameaçadora. Tal resposta inicia o retorno do organismo à homeostase. Entretanto, com frequência, a resposta ao estresse se mantém ativa, seja em decorrência dos padrões de pensamento do indivíduo, ou devido às circunstâncias que o envolvem (LUNDY-EKMAN, 2004). Em outras palavras, por mais que o organismo do indivíduo empregue força e energia para enfrentar a adversidade, esta somente será totalmente superada quando os ambientes externos e internos, os quais mantém a ameaça viva, forem plenamente e positivamente transformados. Neste ponto, mostra-se relevante ressaltar a forte conexão entre os estados emocionais e a tomada de decisão. Os sinais emocionais não decidem, mas afetam o nosso processo decisório (LUNDY-EKMAN, 2004). Ou seja, até mesmo a decisão de transformação de si próprio e do seu entorno é modulada pelos estados emocionais (LIMA JÚNIOR, ZUANON, 2018). Isso nos leva à profunda reflexão sobre o papel crucial da Arquitetura, do Design e do Planejamento e Gestão Urbanísticos, associados às políticas públicas municipais e estaduais, para a definição da qualidade das emoções que modularão nossos mapas cerebrais e nossas memórias, bem como nossas tomadas de decisão no espaço urbano, como se apropriar ou não deste. 


\section{Metodologia}

A presente pesquisa tem como objeto de estudo os impactos do ambiente urbano da área central da cidade de Campinas (São Paulo - Brasil) sobre as memórias consolidadas nos mapas cerebrais dos seus habitantes/usuários, especialmente no que concerne à modulação destes mapas e memórias pelas emoções e sentimentos, respectivamente relacionados ao medo, risco e insegurança neste espaço. Para tanto, as memórias declarativas semânticas dos participantes da pesquisa, sobre este espaço/lugar, são evocadas e registradas nos depoimentos realizados por estes indivíduos, bem como representadas em desenhos de suas próprias autorias.

Neste sentido, a metodologia compreende três fases distintas: (a) preparação do material para a pesquisa de campo; (b) coleta de informações junto a 266 indivíduos, entre habitantes e usuários; (c) compilação, análise e sistematização dos dados coletados.

$\mathrm{Na}$ (a) fase de preparação, delimita-se o recorte espacial da pesquisa ${ }^{3}$ : início na Avenida Aquidaban; segue pelas Rua Antônio Cesarino, Rua Itu, Avenida Júlio de Mesquita; contorna Centro de Convivência; prossegue até Rua José Évilagelin Junior; desce Rua Guilherme da Silva até Avenida Anchieta; continua pelas Avenida Orosimbo Maia, Rua Culto à Ciência, Rua Hércules C. Florence, Rua Saldanha Marinho, Rua Marquês de Três Rios, Rua Barão de Parnaíba, Rua Dr. Mascarenhas; e segue o Trilho da Fepasa até reencontrar a Avenida Aquidaban. Nessa fase, também é definida a estratégia para a coleta de dados: entrevistas semiestruturadas com os participantes da pesquisa e desenhos à mãolivre.

$\mathrm{Na}$ (b) fase de coleta de informações, são aplicados 266 questionários, durante três meses de trabalho realizado em campo, ao longo do recorte espacial delimitado pela pesquisa, conforme detalhado acima. A seleção do público-alvo contempla a diversidade de pessoas, classes sociais, raças e gêneros, os quais vivenciam a região do centro da cidade. A faixa etária dos entrevistados abrange a idade mínima de 16 anos e a máxima de 80 anos. Os pesquisadores, por meio de abordagem direta aos habitantes/ usuários neste espaço público, iniciam as entrevistas com estes a partir da coleta dos seus dados demográficos. Na sequência, os entrevistados recebem o questionário impresso em papel, para preenchimento a próprio punho, bem como para inserção dos desenhos à mão livre. Neste processo, não há qualquer imposição ou limitação quanto à técnica para realização dos desenhos, ou com relação ao tempo dedicado a estes. Esse procedimento visa evitar qualquer interferência na reação emocional ou no processo de evocação das memórias dos inquiridos.

A (c) fase de compilação, análise e sistematização dos dados, inicialmente, consiste na compilação dos dados registrados nas entrevistas e nos questionários. Na sequência, a análise desse conjunto de dados compilados dedica-se à identificação: 1) dos espaços/lugares evocados das memó- 
rias dos participantes; 2) de associações entre os espaços/lugares evocados e a emoção de medo e os sentimentos de risco e insegurança, expressos por estes participantes; 3 ) de possíveis correlações entre todos os depoimentos e os desenhos realizados. Por fim, os resultados quantitativos e qualitativos são sistematizados. Os resultados quantitativos, sistematizados em tabela, evidenciam a predominância temática das memórias evocadas dos mapas cerebrais dos habitantes/usuários. Enquanto os resultados qualitativos discorrem sobre os principais problemas identificados neste espaço urbano e seus impactos ao bem-estar, à qualidade de vida e à saúde dos habitantes/ usuários da cidade de Campinas, conforme detalhado na próxima seção.

\section{Resultados/discussões}

As populações das grandes cidades, como Campinas (São Paulo Brasil), enfrentam dificuldades de várias ordens devido à urbanização acelerada, sem um devido planejamento e gestão urbanísticos. Os problemas são diversos, dentre os quais se destacam: os impactos negativos ao meio ambiente; a desigualdade social; o desemprego; a falta de investimento em áreas como saúde, educação, segurança pública e infraestrutura, dentre tantos outros. Essa gama de problemas urbanos se articula em um sistema que aciona reações negativas em cascata. Tais reações somente são passíveis de contenção e reversão com a aplicação extensiva de políticas públicas, direcionadas a prover os recursos e as condições necessárias à preservação e à manutenção da qualidade de vida dos habitantes/usuários da cidade.

$\mathrm{Na}$ opinião dos inquiridos por essa pesquisa, problemas como esses são observados no cotidiano do centro de Campinas. Foi o grupo de pessoas mais jovens (até 40 anos), independentemente de classe social e gênero, os que mais expressam emoção de medo e declaram sentimentos de risco e de insegurança. A faixa de renda predominante desse grupo é de 3 a 5 salários mínimos ${ }^{4}$.

Um exame mais detalhado permite apontar alguns elementos relevantes (gatilhos), os quais configuram o ambiente de medo, risco e insegurança retratado pelos habitantes/usuários da área central de Campinas. A violência constitui um ponto de bastante inquietação por parte dos frequentadores do centro. Para Vinícius (18 anos, estudante), "são os mendigos e ladrões" os piores problemas do centro. Para ele, é necessário "tirar os mendigos da rua e ter mais polícia para não ter muito assalto". Para Ruan (19 anos, estudante), os problemas do centro são "os ladrões e as pessoas que pedem dinheiro nas ruas". Para Aline (16 anos, estudante), os problemas são "a falta de segurança, os mendigos, os assaltos, a poluição visual, sonora, as calçadas e ruas sujas". Segundo Carlos (16 anos, estudante), os problemas são "muito mendigos, crianças de rua e poluição". Quando indagados sobre o que gostavam no centro, que hoje não existe mais, Rafael (37 anos, 5-10 salários, auxiliar de escritório) relata que sente falta da "tranqui- 
lidade de andar no centro de Campinas sem medo"; Cassiana (26 anos, 1-3 salários, recepcionista) almeja "tranquilidade para poder caminhar pelo centro, sem ter que se preocupar com assaltos"; e João (68 anos, +10 salários, aposentado) "tranquilidade de caminhar com segurança".

A tabela a seguir evidencia na primeira coluna a pergunta aplicada aos entrevistados; na segunda, a classificação dos problemas por categorias; e, na terceira, a tabulação geral das respostas obtidas.

\begin{tabular}{|c|c|c|}
\hline Pergunta & Problemas & Aspectos Identificados \\
\hline \multirow{4}{*}{$\begin{array}{l}\text { Ao se falar em cen- } \\
\text { tro, qual a primeira } \\
\text { coisa que te vem à } \\
\text { mente? }\end{array}$} & $\begin{array}{l}\text { Insegurança } \\
(11)\end{array}$ & Medo/violência (11) \\
\hline & Poluição (12) & Poluição atmosférica, visual e sonora (12) \\
\hline & $\begin{array}{l}\text { Degradação da } \\
\text { infraestrutura } \\
\text { (14) }\end{array}$ & $\begin{array}{l}\text { Sujeira (6); calçadas/ruas estreitas (3); falta de melhorias urbanas } \\
\text { (3); estado de conservação ruim (2) }\end{array}$ \\
\hline & $\begin{array}{l}\text { Descaso políti- } \\
\text { co social (17) }\end{array}$ & $\begin{array}{l}\text { Mendigos/crianças de rua (9); desorganização (5); descaso } \\
\text { público (3) }\end{array}$ \\
\hline \multirow{4}{*}{$\begin{array}{l}0 \text { que você gostava } \\
\text { no centro que se } \\
\text { perdeu? }\end{array}$} & Segurança (98) & Ausência de violência (69); tranquilidade (29) \\
\hline & $\begin{array}{l}\text { Planejamento e } \\
\text { infraestrutura } \\
(62)\end{array}$ & $\begin{array}{l}\text { Limpeza (38); mais agradável (11); mais bonito (4); iluminação } \\
\text { (3); calçadas mais conservadas (2); com banheiros públicos (2); } \\
\text { ruas menos esburacadas (2) }\end{array}$ \\
\hline & $\begin{array}{l}\text { Igualdade } \\
\text { social (56) }\end{array}$ & $\begin{array}{l}\text { Organizado (29); sem mendigos (16); sem camelôs/ambulantes } \\
\text { (8); sem prostituição (3) }\end{array}$ \\
\hline & $\begin{array}{l}\text { Salubridade/ } \\
\text { limpeza (19) }\end{array}$ & $\begin{array}{l}\text { Sem vandalismo/pichação (7); sem poluição visual (5); sem } \\
\text { poluição sonora (5); sem poluição atmosférica (2) }\end{array}$ \\
\hline \multirow{3}{*}{$\begin{array}{l}\text { Qual o centro que } \\
\text { você gostaria? }\end{array}$} & Segurança (6) & Mais seguro/sem medo (3) \\
\hline & $\begin{array}{l}\text { Igualdade } \\
\text { social (6) }\end{array}$ & Sem pedintes (3); sem prostituição (3) \\
\hline & $\begin{array}{l}\text { Planejamento } \\
(5)\end{array}$ & Limpo (2); melhor estado de conservação (2); mais arborizado (1) \\
\hline \multirow{4}{*}{$\begin{array}{l}\text { Na sua opinião, quais } \\
\text { os principais prob- } \\
\text { lemas do centro? }\end{array}$} & Violência (122) & Medo/insegurança \\
\hline & $\begin{array}{l}\text { Degradação da } \\
\text { infraestrutura } \\
(106)\end{array}$ & $\begin{array}{l}\text { Sujeira (42); calçadas/ruas esburacadas (19); calçadas/ruas } \\
\text { estreitas (9); enchentes (7); falta de espaço (5); falta de banheiros } \\
\text { públicos/cheiro de urina (5); falta de arborização (4); falta de } \\
\text { infraestrutura (4); falta de sinalização (3); feiura (3); falta de } \\
\text { conservação (3); falta de iluminaçâa (2) }\end{array}$ \\
\hline & $\begin{array}{l}\text { Descaso políti- } \\
\text { co social ( } 71)\end{array}$ & $\begin{array}{l}\text { Mendigos (33); ambulantes (14); falta de organização (11); falta } \\
\text { de educação das pessoas (9); prostituição (4) }\end{array}$ \\
\hline & $\begin{array}{l}\text { Degradação da } \\
\text { infraestrutura/ } \\
\text { poluição }(59)\end{array}$ & $\begin{array}{l}\text { Vandalismo/pichação (22); poluição atmosférica (15); poluição } \\
\text { visual (10); poluição sonora (6); destruição do patrimônio (6). }\end{array}$ \\
\hline
\end{tabular}

Embora seja um aspecto frequente desta região central, como um todo, a violência acontece de forma mais acentuada em determinados territórios, como no entorno da Praça Silvia Simões e na área conhecida como Boca do Lixo. $O$ centro da cidade de Campinas ainda é marcado por diversos pontos de prostituição, fato que também corrobora à sua degradação física. 
Quanto aos principais problemas relacionados à infraestrutura do centro da cidade, destacam-se os depoimentos de: Ingrid (19 anos, estudante), que relata "(há) falta de organização, muitas pichações e sujeira"; João Carolino (58 anos, 1-3 salários, porteiro), que destaca a ineficácia da estrutura existente para o escoamento da água de chuva, "quando chove as ruas inundam facilmente".

Na sequência, discute-se os principais problemas urbanos levantados pelos participantes da pesquisa e seus impactos às memórias consolidadas e, consequentemente, ao equilíbrio e à qualidade de vida dos habitantes/usuários do centro da cidade.

Depredação e poluição: deflagradores à inexistência de identificação e à aversão ao espaço urbano

O sentimento de identificação, afeto e pertencimento ao espaço/ lugar reservado na memória individual e/ou coletiva é consolidado nos mapas cerebrais dos habitantes/usuários de uma cidade, a partir de construções e reconstruções de significados, sentidos e valores que são atribuídos a este espaço/lugar ao longo de suas vidas. Esse processo tem seu início na apropriação do espaço/lugar por estes habitantes. Tal apropriação impulsiona os indivíduos a vivenciarem este espaço/lugar em sua totalidade e estabelecer com este uma relação de identidade concreta e/ou subjetiva. Por exemplo, isso ocorre quando os habitantes/usuários conseguem desenvolver, neste espaço/lugar, valores próximos aos seus sentimentos e à sua identidade cultural e simbólica.
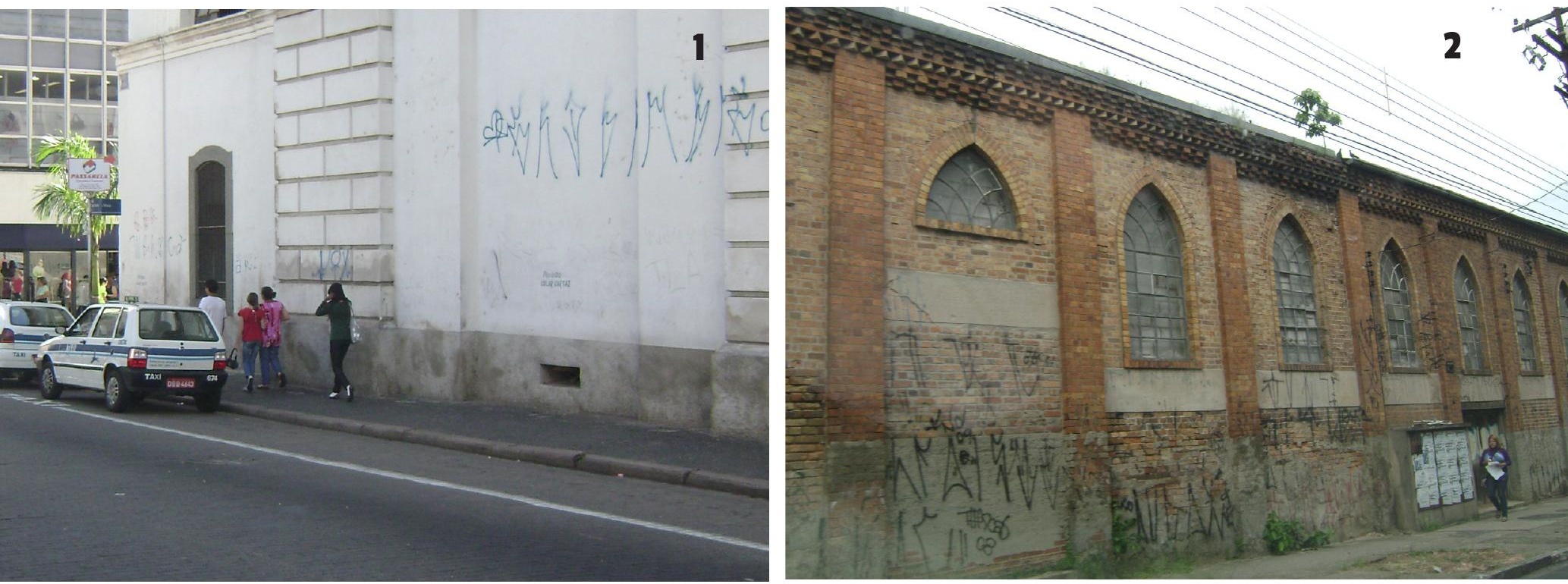

Fig 1. Pichações nas fachadas de imóveis reconhecidos como Patrimônio Cultural Campineiro. 1.

Fachada posterior da Catedral. 2. Fachada da antiga Fábrica Lidgerwood

Fonte: autores 
Nas nossas experiências sociais, as emoções, sejam elas positivas ou negativas, assim como os sentimentos posteriores a estas, tornam-se componentes obrigatórios e fundamentais para o sentimento de afeto e de pertencimento ou não pertencimento a um determinado espaço/lugar.

Atualmente, diversos problemas urbanos identificados na área central de Campinas corroboram a experiências sociais que deflagram emoções negativas em seus habitantes/usuários e despertam o sentimento de não pertencimento ao espaço/lugar, como nos casos referentes à pichação de imóveis (Figura 1).

Mesmo com a implementação do plano antipichação, pela Prefeitura Municipal, os edifícios permanecem danificados e o centro da cidade com aspecto sujo. Ambos os fatos corroboram sobremaneira à imagem de total descaso com o patrimônio, a qual retroalimenta a perda de identificação e de afeto, assim como o sentimento de não pertencimento a este espaço/ lugar pelos habitantes/usuários.

Nos desenhos realizados pelos participantes dessa pesquisa, a pichação se constitui em um elemento bastante destacado, no que tange aos problemas urbanos. Na figura 2, Lucas e Gabriel exibem edifícios pichados, com referências à poluição visual. Lucas ainda acrescenta opinião crítica a essa prática, com a frase: "o centro de Campinas pra mim tem muita pichação". Na figura 3, no desenho de João, propagandas e letreiros dos estabelecimentos se confundem à poluição produzida pelos carros e definem um ambiente urbano inóspito. Enquanto o desenho de Rodrigo caracteriza o centro como um "buraco" em uma representação irônica e depreciativa da área central de Campinas.

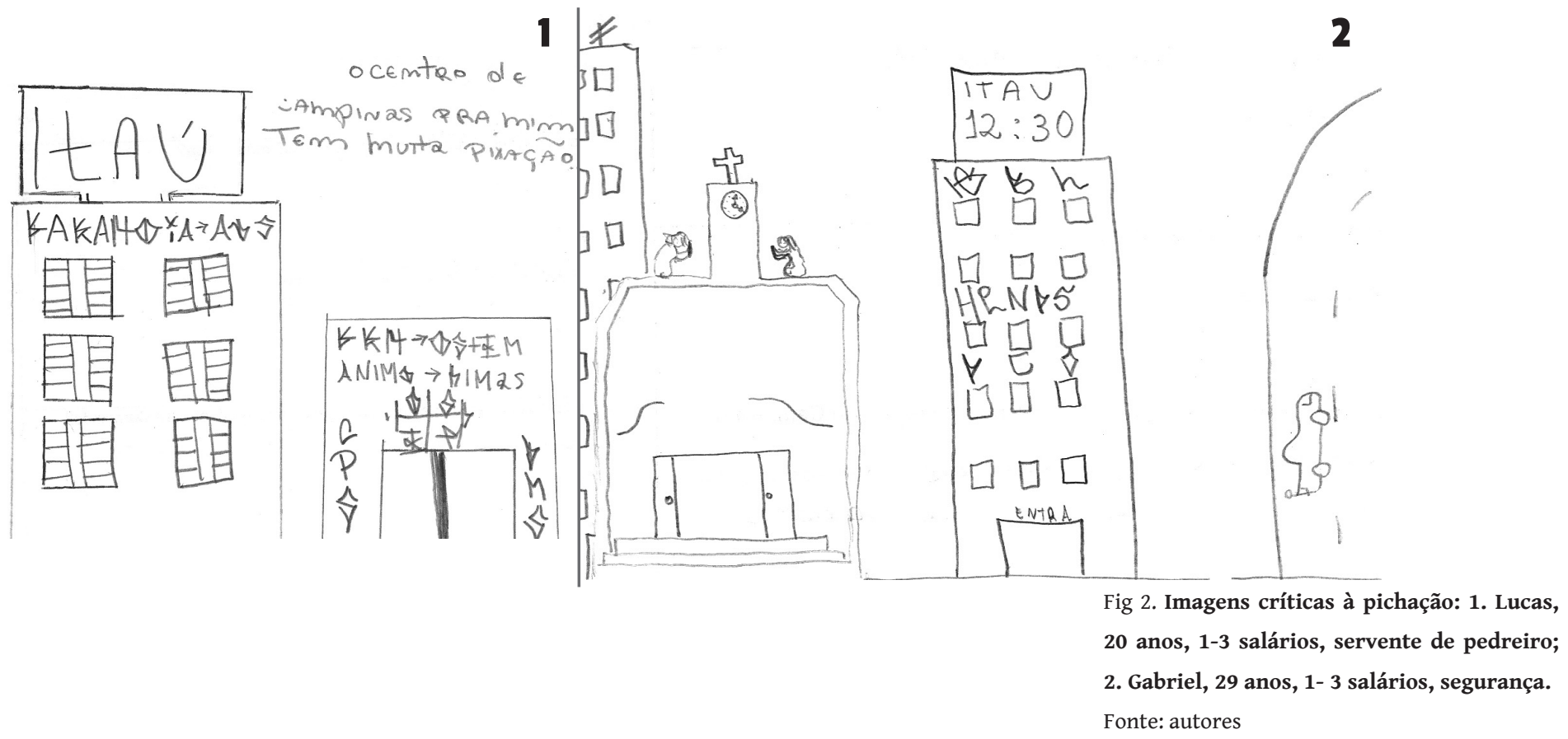


sem qualquer motivo imediato e aparente para tal. Ou ainda, ser evocada em outro espaço/local semelhante aquele da infância. Ou seja, mesmo sem uma causa imediata e aparente existente neste espaço/local do presente, que justifique o medo sentido pelo indivíduo naquele momento, seus mapas cerebrais registram a memória emocional de sua infância naquele ambiente, e o menor estímulo pode ser suficiente para evocá-la (DAMÁSIO, 2004).

Nesse contexto, é possível exemplificar o caso do Viaduto Cury em Campinas: "Quem lembra como era aquele lugar onde hoje está o terminal sente saudade. Era um jardim lindo! Hoje, a droga e a violência tomaram conta" (GALLACCI, 2010). Isso se evidencia, também na declaração de alguns entrevistados:

\footnotetext{
O jardim do centro do Viaduto Cury, onde havia o relógio do sol e com áreas de lazer, infelizmente foi transformado em terminal de ônibus e num desorganizado e sujo mercado popular na entrada da cidade (Tânia, 58 anos, 5-10 salários, secretária);

Sinto falta do lago que existia no Viaduto Cury (Júlio, 46 anos, 5-10 salários, designer);
}

Que saudade do jardim que tinha no lugar do Terminal Central (Juliana, 31 anos, 5-10 salários, publicitária).

Estes depoimentos retratam as situações que emergem das memórias emocionais destes habitantes/usuários, aqui evocadas e relacionadas ao medo desencadeado pela violência urbana no centro da cidade de Campinas. Imagens mentais implícitas que constroem os mapas cerebrais destes três participantes, a partir das experiências vivenciadas naquele espaço em diferentes momentos das suas vidas. Tais imagens mentais agora se explicitam nas memórias evocadas e nos respectivos relatos.

Melgaço (2008, p. 451) define violência como "todos os atos lesivos aos interesses individuais e sociais, quer sejam eles reconhecidos pelo direito ou não". Enquanto Yázigi (2000) defende que a violência está organizada em múltiplas inter-relações: "com o comércio estabelecido e o informal; com a rede de drogas; com o esquema de prostituição masculina e feminina" (p. 253). O fato é que estes atos lesivos, articulados nestas múltiplas inter-relações, alteram a rotina de diversos habitantes/usuários do centro da cidade. Comerciantes são obrigados a fechar seus estabelecimentos mais cedo, e estudantes a voltar da escola em grupo, ambos com o intuito de minimizar as chances de assalto. Conforme artigo do jornal Correio Popular (Campinas de 23 de maio de 2010), a violência impõe um "toque de recolher no centro". Antônio Cardoso Júnior, comerciante nesta região da cidade, relata: 
Um começa a fechar e os outros vão atrás. É uma espécie de toque de recolher mesmo (...) a gente costumava fechar mais tarde. Mas passamos a encerrar (as atividades) às $18 \mathrm{hs}$ por medo da violência. Estou fechando no horário em que eu mais poderia faturar, quando as pessoas saem do trabalho e passam por aqui para voltar para casa (GALLACCI, 2010).

Como ressalta Jacobs (2001), são os donos de padaria, lanchonetes, lojas, mercearias e outros pequenos estabelecimentos que mantém os "olhos atentos" e assumem a posição de "proprietários naturais da rua", os quais usam e vigiam o espaço urbano durante todo o tempo.

Nas palavras de Melgaço (2008, p. 450), "é a cultura do medo, fruto da violência da informação promovida pela mídia, o principal incentivo para o surgimento de formas urbanas segregadoras e violentas". Tais como esse 'toque de recolher implícito', registrado como estímulo condicionado nas memórias emocionais dos comerciantes da área central, em especial no perímetro situado entre a Avenida Francisco Glicério e a antiga Estação da Fepasa (no sentido leste-oeste), e entre o Terminal Central até as imediações da antiga rodoviária (sentido norte-sul). Importante ressaltar que dentro deste perímetro, no entorno do Complexo Ferroviário (ao perpassar as ruas Saldanha Marinho, Visconde do Rio Branco, Ferreira Penteado, Costa Aguiar e a região da Praça Marechal Floriano Peixoto) situa-se a "Boca do Lixo", região que concentra ações de contrabando, falsificação e prostituição, as quais corroboram sobremaneira à consolidação dessas memórias nos mapas cerebrais dos habitantes/usuários da cidade.

Em decorrência disso, essa região permanece como um entrave à reabilitação urbana do centro. Em entrevista ao jornal Correio Popular de Campinas, a arquiteta Débora Frazatto destaca:

\footnotetext{
As pessoas não querem morar em uma região sem atrativos. Os bancos e lojas fecham no final da tarde. E ruas desertas viram campo fértil para a marginalidade. A comunidade precisa ter atrações culturais, estabelecimentos comerciais funcionando em qualquer hora. O Centro precisa ter vida (FÉLIX e VERZIGNASSE, 2010, pg. A6).
}

Em outras palavras, esse 'toque de recolher implícito' não somente restringe o uso do espaço urbano, como também impede os habitantes/usuários de 'viverem a cidade' e, por consequência, 'dar vida' a seus equipamentos. 
capazes de garantir o bem-estar e a saúde da população. Descreve uma praça que, pela presença do Palácio da Justiça, provavelmente se trata do Largo do Rosário. Na mesma, verifica-se ainda uma banca de jornal, um carrinho de pipoca e crianças jogando milho para pombos, características marcantes desse espaço, relacionadas à qualidade de vida.

Imbuídos desse mesmo sentimento, algumas pessoas manifestaram saudade da utilização segura da praças e jardins, como, por exemplo, do convívio e footing. Norton (33 anos, mais de 10 salários, professor) anseia por "praças mais bem cuidadas, com áreas verdes, locais de convivência e um lugar seguro para passear à noite". Marina (58 anos, 5-10 salários, contadora) deseja "mais praças, crianças brincando, lugar para passear, ponto de encontro e lazer". A praça é signo do lugar, síntese do espaço intraurbano em que está inserida, carregada de simbologias e memória. Por isso torna-se um referencial de civilidade e de qualidade de vida urbana.

\section{Conclusão}

Este artigo busca evidenciar a atuação dos problemas urbanos como verdadeiros gatilhos, ou seja, como estímulos que disparam emoções e sentimentos negativos nos habitantes/usuários de uma cidade, aqui especificamente retratada pelo centro da cidade brasileira denominada como Campinas.

Tais gatilhos deflagram uma vagarosa e silenciosa, mas intensa reação em cadeia. Pouco a pouco, as experiências vivenciadas neste centro, reconfigurado por inúmeros problemas, se acumulam nas sucessivas imagens mentais que os cérebros de seus habitantes/usuários são capazes de armazenar. Imagens que desencadeiam emoções de medo. Emoções de medo que são sentidas como risco à vida e insegurança. São essas as imagens mentais que predominam nos mapas cerebrais dos participantes desta pesquisa, e aqui vêm à tona como memórias externalizadas nos depoimentos e/ ou nos desenhos realizados por estes. $O$ centro campineiro, popularmente reconhecido como o espaço/lugar da cidade que concentra o consumo de mercadorias, assim como as atividades de lazer, é evocado das memórias dos seus habitantes/usuários como o espaço/lugar do medo, do risco e da insegurança. Essas memórias, claramente moduladas por este conjunto de emoção e sentimento, evocam violência, poluição, engarrafamento, desemprego, desigualdade social, infraestrutura precária, falta de embelezamento urbano, entre tantos outros problemas que residem nos espaços físico da cidade e mental da população.

A vagarosa, silenciosa, mas intensa reação em cadeia eclode no desafeto involuntário à região central. Um desafeto alicerçado no conjunto de emoção, sentimento e memória supracitado e erguido lentamente no imaginário popular. Esse desafeto, mesmo que involuntário, compromete o desejo pelo espaço/lugar que guiaria o habitante/usuário à tomada de decisão de se apropriar deste ambiente urbano. Pelo contrário, a repulsa preponde- 
ra e sustenta os entraves à refuncionalização do centro. Em outras palavras, o sentimento de insegurança decorrente do medo da violência e do risco à própria vida leva o indivíduo a não desejar morar, tampouco frequentar os bares, os restaurantes e as atividades culturais disponíveis na área central. Consequentemente, imóveis se degradam pela falta de uso; valores históricos e sociais são esquecidos, ou colocados em segundo plano; a imagem do centro como o lugar mais importante e seguro da cidade - como realmente o foi no passado - se deteriora; e a reação em cadeia é retroalimentada.

Mas, como interromper e reverter este processo cíclico de degradação e abandono? Aqui importa reiterar a relevância de se compreender que o sentimento de identificação e de pertencimento ao espaço/lugar é algo a ser resgatado e reconstruído, pouco a pouco. É necessário que os dinâmicos mapas cerebrais dos habitantes/usuários sejam reconfigurados. E as antigas imagens mentais, alimentadas pelo medo, sejam substituídas por novas imagens mentais. Ou seja, por imagens mentais formadas a partir de emoções e sentimentos positivos, advindos da experiência prazerosa no espaço/lugar. Algo que solicita abandonar a condição passiva, nas esferas pública e privada, para romper as barreiras erguidas pelos problemas urbanos e construir uma outra paisagem, agora alinhada aos desejos voluntários dos habitantes/usuários da cidade. Nisso reside a significativa contribuição que a cooperação entre os campos da Arquitetura, do Design, do Planejamento e Gestão Urbanísticos e da Neurociência pode trazer ao disponibilizar a tais esferas instrumentalizações capazes de assegurar o bem-estar e a qualidade de vida nas relações cotidianas entre as pessoas e os espaços/lugares, assim como a saúde geral da população.

Neste caminho, como desdobramento futuro, a pesquisa adicionará outras possíveis camadas de interpretação aos resultados aqui discutidos, advindos das informações neurofisiológicas obtidas por meio de dispositivos de rastreamento ocular (Eye Tracking) e de monitoramento da variabilidade emocional dos habitantes/usuários da cidade.

1 "Homens lentos" é uma categoria definida pelo geógrafo Milton Santos [1] para se referir aos sujeitos que estão fora da velocidade dos processos hegemônicos, ou seja, fazem parte das dinâmicas espaciais que "vem de baixo" - personifica o homem comum, pobre.

2 Campinas é um município do interior do estado de São Paulo, localizado a aproximadamente $100 \mathrm{~km}$ da capital São Paulo. Segundo o site da Prefeitura Municipal de Campinas (http://www.campinas.sp.gov.br) [2] o município possui 1.091 .946 habitantes e a Região Metropolitana de Campinas composta por 20 municípios, possui 3.094 .181 habitantes. Campinas possui um nível de industrialização elevado e aproximadamente $70 \%$ da sua economia advém do setor de serviços.

3 Ao longo da pesquisa identificou-se que as Secretarias da Prefeitura Municipal de Campinas adotam perímetros distintos para definir a área central. Esses perímetros foram sobrepostos e optou-se por delimitar um recorte ampliado que abrangesse todos eles. 


\begin{abstract}
40 valor do salário mínimo no Brasil em janeiro de 2020 corresponde a $\mathrm{R} \$ 1.039,00$, o que equivale a aproximadamente $U \$ 224,00$.

5 Segundo a Carta de Lisboa de 1995, a reabilitação urbana é uma estratégia de gestão urbana, que procura requalificar a cidade existente, por meio de intervenções múltiplas destinadas a valorizar as potencialidades sociais, econômicas e funcionais, a fim de melhorar a qualidade de vida das populações residentes.
\end{abstract}

\section{Referências}

CAMMAROTA, M.; BEVILAQUA, L. R. M.; IZQUIERDO, I. Memória. In: LENT, Roberto: Neurociência da mente e do comportamento. Porto Alegre: Guanabara Koogan, 2008.

CARTA de Lisboa sobre a reabilitação urbana integrada, 2005.

DAMÁSIO, A. E o cérebro criou o homem. São Paulo: Companhia das Letras, 2011.

DAMÁSIO, A. Em busca de Espinosa: prazer e dor na ciência dos sentimentos. São Paulo: Companhia das Letras, 2004.

FÉLIX, L.; VERZIGNASSE, R. Boca do lixo expõe a decadência do centro. Correio Popular, Campinas, Cidades, 02 mai. 2010.

GALLACCI, F. Violência impõe toque de recolher no Centro. Correio Popular, Campinas, Cidades, 23 mai. 2010.

IZQUIERDO, I. Memória. Porto Alegre: Artmed, 2011.

JACOBS, J. Morte e vida de grandes cidades. São Paulo: Martins Fontes, 2001.

LEFEBVRE, H. La production de l'espace. 15nd edn. Paris: Anthropos, 1974.

LIMA JÚNIOR, G. C., ZUANON, R. SEE BEYOND contributions to the project-based practice of sighted and visually impaired students in the context of higher education in Design. DAT Journal, v. 3, n. 2, p. 203-231, 2018. https://doi.org/10.29147/dat.v3i2.91

LUNDY-EKMAN, L. Neurociência: fundamentos para reabilitação. Rio de Janeiro: Elsevier, 2004. MELGAÇO, L. M. Território em atrito: a violência sob o olhar da complexidade dialética. In: SOUZA, M. A. A. (ed.). A Metrópole e o futuro: refletindo sobre Campinas. Campinas: Territorial, 2008.

PREFEITURA Municipal de Campinas. In: Homepage, 2018. http://www.campinas.sp.gov.br. Acesso em fev. 2020.

SANTOS, M. Técnica, espaço e tempo: globalização e meio técnico-científico informacional. São Paulo: Hucitec, 1994.

TUAN, Yi-Fu. Paisagens do medo. São Paulo: Unesp, 1995.

YÁZIGI, E. O mundo das calçadas. Por uma política democrática de espaços públicos. São Paulo: Humanitas/FFLCH/Imprensa Oficial do Estado, 2000.

Recebido: 20 de fevereiro de 2020 . Aprovado: 02 de março de 2020.
YOUNG, A. W. et al. Face processing impairments after amygdalotomy. Brain: A Journal of Neurology, 118(1), 15-24, 1995. doi.org/10.1093/brain/118.1.15. 